\title{
Review of Ceranisus (Hymenoptera: Eulophidae) of Turkey, with description of a new species
}

\author{
Miktat DOĞANLAR ${ }^{1}$ and Serguei V. TRIAPITSYN ${ }^{2}$ \\ ${ }^{1}$ Mustafa Kemal University, Agriculture Faculty, Plant Protection Department, Tayfur Sökmen Kampüsü, 31034 Serinyol, Antakya, \\ Hatay, Turkey; e-mail: mikdoganlar@yahoo.com.tr \\ ${ }^{2}$ Entomology Research Museum, Department of Entomology, University of California, Riverside, CA 92521, USA
}

Key words. Taxonomy, Hymenoptera, Eulophidae, Ceranisus, new species, Turkey

\begin{abstract}
Three species of Ceranisus Walker, 1841 (Hymenoptera: Eulophidae: Entedoninae) were collected recently in Turkey, including C. menes (Walker, 1839) and C. pacuvius (Walker, 1841) in southeastern Anatolia. A new species, C. hirsutus Doğanlar \& S. Triapitsyn, is described from Şanliurfa Province. The genus Urfacus Doğanlar, 2003 is synonymized under Ceranisus and its type species, U. bozovaensis Doğanlar, 2003 is transferred to Ceranisus as C. bozovaensis (Doğanlar, 2003) comb. n., and the species is redescribed from the new material. An identification key to both sexes of Ceranisus from Turkey and Europe is provided.
\end{abstract}

\section{INTRODUCTION}

The thrips-attacking genus Ceranisus Walker, 1841 (Hymenoptera: Eulophidae: Entedoninae) is a member of a natural, apparently monophyletic group of four genera within the subfamily Entedoninae (Hymenoptera: Eulophidae), all of which are larval parasitoids of thrips (Thysanoptera) (Schauff, 1991; Triapitsyn \& Headrick, 1995; Loomans, 2003; Triapitsyn, 2005; Triapitsyn \& Morse, 2005). Another genus, Urfacus Doğanlar, 2003, was recently described from Turkey (Doğanlar, 2003). Its true identity was not clear (Triapitsyn, 2005) until now when, based on the new material collected in Turkey by the senior author of this communication during 2005, it has become obvious that it should be regarded as a new synonym of Ceranisus.

In Europe, the species of Ceranisus were first keyed by Graham (1963), who also described a new species, $C$. lepidotus, from Great Britain. Erdös (1966) then described $C$. planitianus from Hungary. More recently, Cameron et al. (2004) described a new species, C. antalyacus S. Triapitsyn, 2004, from the Asian part of Turkey (Antalya) and compared it with the related Holarctic species of the genus. Triapitsyn \& Headrick (1995) reviewed the Nearctic species of Ceranisus; Triapitsyn \& Morse (2005) revised the New World fauna of the genus. Triapitsyn (2005) gave a world taxonomic revision of Ceranisus and three other related entedonine genera of thrips parasitoids, and listed their known host associations. Earlier, Loomans \& van Lenteren (1995) provided a nice overview of the described thrips parasitoids and their importance for biological control of thrips pests. The present study adds an interesting, very unusual new species of Ceranisus from Turkey and corrects the descriptions of the female and male of C. bozovaensis (Doğanlar, 2003), comb. n. from Urfacus. Identification keys to both sexes of Ceranisus in Europe and Turkey are also provided.

\section{MATERIAL AND METHODS}

Morphological terminology follows Gibson (1997). This study is based upon examination and identification of about 100 specimens collected from the southern and southeastern Anatolia, some of which were slide-mounted in Canada balsam. The examined specimens were deposited in the collections indicated by the following acronyms: ICMKU, Insect Museum of Plant Protection Department, Agriculture Faculty, Mustafa Kemal University, Antakya, Hatay, Turkey, and UCRC, Entomology Research Museum, Department of Entomology, University of California, Riverside, California, USA. Abbreviations used in the key and descriptions are: $\mathrm{C}=$ Claval antenomere, and $\mathrm{F}=$ Funicular antenomere.

\section{Genus Ceranisus Walker, 1841}

Figs 1-18

Ceranisus Walker, 1841: vi, pl. N, Fig. 2. Type species: Cirrospilus pacuvius Walker, 1841 by monotypy.

Ceranisus: Triapitsyn, 2005: 288-307 (world revision including list of synonyms, diagnosis, key to females).

Urfacus Doğanlar, 2003: 182. Type species: Urfacus bozovaensis Doğanlar; 2003 by monotypy and original designation. Syn. n.

\section{Diagnosis}

Body and appendages yellow to dark brown or black; occipital suture present and conspicuous (can be straight, sinuate, or angulate); frontal grooves reaching eye at level of anterior (median) ocellus; malar sulcus present and straight in most species, very rarely split (Y-shaped); mandible reduced (without teeth); female flagellum with 2 funicle segments and a distinct 2-or 3-segmented clava (usually 2-segmented but 3-segmented in C. russelli (Crawford, 1911) and C. hirsutus Doğanlar \& Triapitsyn sp. n.), apical claval segment with an apical spicula in both sexes; male antenna often with a swollen scape, male flagellum with 2-segmented funicle and 3-segmented clava; mesosoma usually smooth or at most lightly sculptured but distinctly reticulate in C. lepidotus Graham, 
1963 and C. bozovaensis (Doğanlar, 2003) comb. n.; notauli indistinct, sometimes distinct but faint; midlobe of mesoscutum with 2 pairs of setae (except with 1 such pair in most $C$. russelli and with 4 pairs in $C$. hirsutus); anterior margin of scutellum straight; scutellum with 1 pair of setae except in $C$. hirsutus with more than 4 pairs; forewing broadened beyond submarginal vein; marginal vein of forewing not expanded except in males of $C$. bozovaensis notably expanded, especially basally, in some of the specimens; petiole at most as long as wide, notably wider than long.

\section{Keys to species in Europe and Turkey}

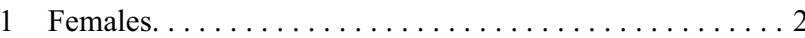

Males. .............................. 8

2 Clava 3-segmented (Fig. 1); midlobe of mesoscutum with 4 pairs of setae, scutellum with at least 4 pairs of setae, and axilla with 2 setae (Fig. 3); stigmal vein of forewing distinctly petiolate (Fig. 4) . . . . . . . . C. hirsutus $\mathrm{sp} . \mathrm{n}$. Clava 2-segmented (Figs 11, 16); midlobe of mesoscutum with 2 pairs of setae, scutellum with 1 pair of setae, and axilla with 1 seta (Fig. 14); stigmal vein of forewing short, wide, and sessile . . . . . . . . . . . . . . . . 3

3 Head and mesosoma distinctly reticulate .......... 4

- Head and mesosoma smooth or lightly sculptured ...... . 5

4 Head and mesosoma dark brown to bluish-black. . . . . . . . . . C. bozovaensis (Doğanlar) comb. $\mathrm{n}$. Head and mesosoma with obvious dark green metallic luster dorsally . . . . . . . . . . . . . . . . . . C. lepidotus Graham

5 Forewing blade with a distinct semi-oval bare area at posterior margin behind base of marginal vein, demarcated anteriorly by a sinuate line of setae. . . . . . . . . . . 6

Forewing blade either without such bare area or, if a narrow bare area present along posterior margin behind base of marginal vein, it is demarcated anteriorly by a more or less straight cubital setal line (Figs 12,18) . . . . . . . . 7

6 Malar groove entire and straight; at least base of gaster yellow or light brown ........... C. menes (Walker) - Malar groove split (Y-shaped); gaster completely dark brown or black ............. C. planitianus Erdös

7 Basal claval segment at most 1.1x distal segment (Fig. 16). . C. pacuvius (Walker)

- Basal claval segment at least $1.3 \mathrm{x}$ as long as distal segment . .................... C. antalyacus $\mathrm{S}$. Triapitsyn

8 F1 very small, less than $1 / 2$ size of F2 (Fig. 2); midlobe of mesoscutum with 4 pairs of setae, scutellum with at least 4 pairs of setae, and axilla with 2 setae (as in Fig. 3); stigmal vein of forewing distinctly petiolate (as in Fig. 4) . . . . . . . F1 at most a little smaller than F2 (Figs 7,17 ); midlobe of mesoscutum with 2 pairs of setae, scutellum with 1 pair of setae, and axilla with 1 or 2 setae (Fig. 9); stigmal vein of forewing short, wide, and sessile . . . . . . . . . 9

9 Head and mesosoma distinctly reticulate . . . . . . . . . 10

- Head and mesosoma smooth or lightly sculptured ..... . 11

10 Head and mesosoma dark brown to bluish-black; marginal vein of forewing usually notably expanded, especially basally (Fig. 8). . . . . . C. bozovaensis (Doğanlar) comb. n.

- Head and mesosoma with obvious dark green metallic luster dorsally; marginal vein slightly thickened in whole length . . C. lepidotus Graham

11 Scape slender, not swollen, or slightly dilated, at least $3 \times$ as long as wide (Fig. 7); forewing blade with a distinct semioval bare area at posterior margin behind base of marginal vein, demarcated anteriorly by a sinuate line of setae . . 12
Scape strongly swollen (Fig. 17); forewing blade either without such bare area or, if a narrow bare area present along posterior margin behind base of marginal vein, it is demarcated anteriorly by a more or less straight cubital setal line. . . . . . . . . . . . . . . . . . . . . 13

12 Malar groove entire and straight; at least base of gaster yellow or light brown; antenna with very long setae . . . . . .

C. menes (Walker)

- Malar groove split (Y-shaped); body entirely black; antenna with relatively short setae ......... . planitianus Erdös

13 Scape $1.4-1.7 \times$ as long as wide (Fig. 17) ......................... pacuvius (Walker)

- Scape 1.8-2.2× as long as wide . C. antalyacus S. Triapitsyn

\section{Ceranisus hirsutus Doğanlar \& S. Triapitsyn, sp. n.}

Figs $1-5$

Types. Holotype $\uparrow$ (on slide, ICMKU), labeled: "TURKEY, Şanliurfa, Bozova, Kangörmez, $37^{\circ} 26^{\prime} \mathrm{N}, 38^{\circ} 12^{\prime} \mathrm{E}, 430 \mathrm{~m}$, 7.v.2005, M. Doganlar. Mounted at UCR/ERM by V.V. Berezovskiy 2005 in Canada balsam". Paratypes (same collection data as the holotype): $1 \delta^{\Uparrow}$ (on slide, in entellelan, ICMKU); 19 (on point, UCRC), $2 \uparrow, 10^{\pi}$ (on points, ICMKU); 19 (in alcohol, ICMKU)

\section{Description}

Female (holotype). Body dark brown; antenna light brown, legs light to dark brown, venation brown.

Head. Vertexal suture broadly V-shaped (Fig. 1). Antenna (Fig. 1) with scape slender, about $4.8 \times$ as long as wide; pedicel $1.8 \times$ longer than wide; F1 notably shorter and narrower than F2, $0.75 \times$ as long as and $0.66 \times$ as wide as F2, without sensilla; F2 with 1 sensillum; clava including spicula $2.0 \times$ as long as wide, $\mathrm{C} 1$ slightly shorter than combined length of $\mathrm{C} 2$ and $\mathrm{C} 3$, distal claval segments subequal in length, $\mathrm{C} 1$ and $\mathrm{C} 2$ with one sensillum each and $\mathrm{C} 3$ with two sensilla.

Mesosoma. (Fig. 3). Almost as long as metasoma; mesoscutum, scutellum, and axillae with light engraved sculpturing, without metallic luster; midlobe of mesoscutum with 8 setae; scutellum with 9 setae. Forewing (Fig. 4) $2.2 \times$ as long as wide; longest marginal cilia about 1/8 maximal forewing width; blade hyaline, uniformly covered with numerous microtrichia; submarginal vein with 2 long macrochaetae and 2 hypochaetae opposite to basal macrochaeta; postmarginal vein $0.7 \times$ as long as stigmal vein, marginal vein + parastigma $4 \times$ as long as stigmal vein, the latter distincly petiolate. Hind wing about $5.5 \times$ as long as wide; blade uniformly setose, hyaline; longest marginal cilia about $1 / 3$ wing's maximal width. Coxae lightly sculptured (with long cells).

Metasoma. Petiole about $2 \times$ as wide as long. Ovipositor occupying about $2 / 3$ length of gaster, slightly exserted; ovipositor length/metatibia length ratio $1.1: 1.4$

Measurements (holotype). Body length: $0.94 \mathrm{~mm}$. Relative measurements, as length or length/width: Antenna: scape: $11.5 / 2.5$; pedicel: 5/2.5; F1: 2/1.5; F2: 1.3/2.3; clava: $5.6+1.5 / 3.5, \mathrm{C} 1: 2.8, \mathrm{C} 2: 2, \mathrm{C} 3: 1$, spicula: 1.5 . Forewing: 56/25; longest marginal cilia: 2.5 . Hind wing: 50/9; longest marginal cilia: 3. Ovipositor: 22.

Male. Similar to female except for normal sexually dimorphic features, as follows. Antenna (Fig. 2) with scape $3.3 \times$ as long as wide; pedicel $1.66 \times$ longer than 

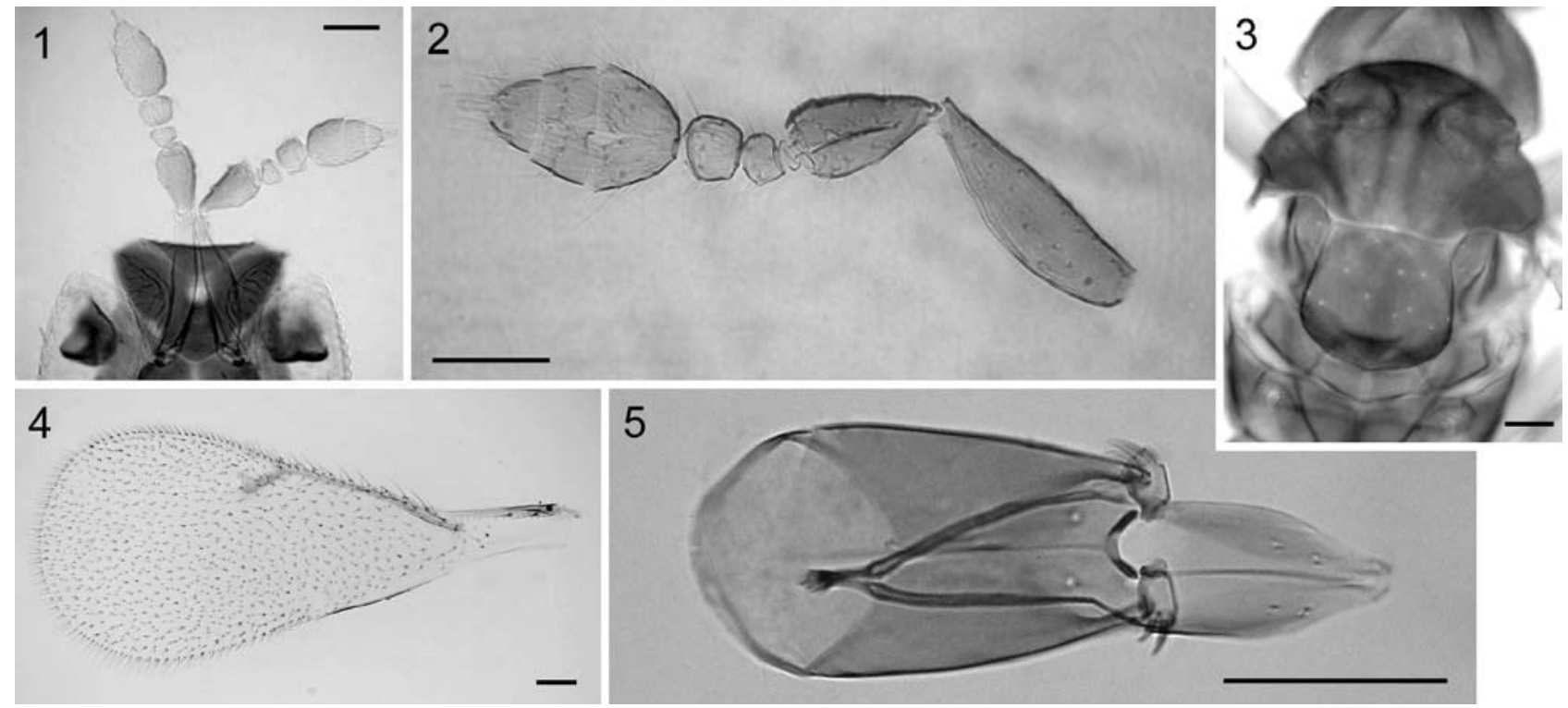

Figs 1-5: Ceranisus hirsutus sp. n. 1 - female head and antennae; 2 - male antenna; 3 - female mesoscutum and scutellum; 4 female forewing; 5 - male genitalia. Scale bars $=0.05 \mathrm{~mm}$.

wide; flagellum as in female but F1 slightly narrower. Genitalia as in Fig. 5. Body length: $1.00 \mathrm{~mm}$. Relative measurements (paratype on slide, as length or length/ width): Antenna: scape: 10/3; pedicel: 5/3; F1: 1.5/2; F2: 2/2.3; clava: 7+1.5/4.5, C1: 3, C2: 2, C3: 2, spicula: 1.5 .

Diagnosis. This species is similar to the North American $C$. russelli in having a 3-segmented clava of the female antenna; thus it would key together with C. russelli in the world key to females of Ceranisus by Triapitsyn (2005). It differs from $C$. russelli and all other described species of Ceranisus in having mesoscutum and scutellum with 8 and 9 setae, respectively (in $C$. russelli mesoscutum and scutellum with 4 and 2 setae, respectively). At present, it cannot be assigned to any species group defined for Ceranisus by Triapitsyn (2005).

Hosts. Unknown.

Etymology. This species is named for its unusually large number of setae on the mesoscutum and scutellum (hirsutus stands for hairy or bristly in Latin).

\section{Ceranisus bozovaensis (Doğanlar, 2003), comb. n.}

Figs 6-15

Urfacus bozovaensis Doğanlar, 2003: 182.

Type locality. Bozova, Şanliurfa, Turkey.

Type material examined. Holotype: $\widehat{o}$ (wrongly indicated as female in the original description), on card (ICMKU), labeled:

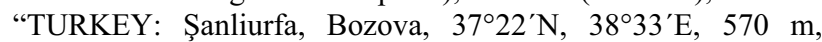
15.vi.2002, M. Doganlar, Urfacus bozovaensis Doğanlar. Mounted by M. Doğanlar". Paratypes (same data as the holotype, ICMKU): 10 (wrongly indicated as female in the original description) and 19 (wrongly indicated as male in the original description) on cards; 10 (wrongly indicated as female in the original description) on slide, mounted in Canada balsam at UCRC by V.V. Berezovskiy in 2005; $1 \delta^{\hat{~}}$ on card (correctly indicated as male in the original description).

Additional material examined. TURKEY: Şanliurfa, Birecik, İnnapli Village, $37^{\circ} 04^{\prime} \mathrm{N}, 37^{\circ} 55^{\prime} \mathrm{E}, 430 \mathrm{~m}, 6 . \mathrm{v} .2005$,

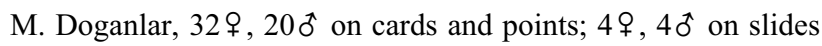

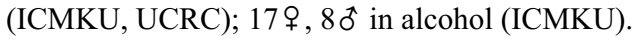

\section{Redescription}

Female. Body dark brown to bluish-black, non-metallic; mouthparts, antenna and tarsi yellow, venation brown.

Head. Vertexal suture broadly V-shaped (as in Fig. 6). Antenna (Fig. 11) with scape slender, about $3.6 \times$ as long as wide; pedicel $2 \times$ as long as wide; F1 slightly longer than F2 (2.5/2.0), slightly longer than broad, and F2 $0.8 \times$ as long as broad, F1 without sensilla, F2 with 1 sensillum; clava including spicula $2.0 \times$ as long as wide, $\mathrm{C} 1$ slightly shorter than C2 (3/4), C1 with one sensillum and C2 with two sensilla.

Mesosoma. Almost as long as metasoma; mesoscutum, scutellum, and axillae with broad meshed reticulate sculpturing; midlobe of mesoscutum with 2 pairs and scutellum with 1 pair setae (Fig. 14). Forewing (Fig. 12) about $2.8 \times$ as long as wide; longest marginal cilia about $1 / 4.4$ maximal width of forewing; blade hyaline, uniformly covered with numerous microtrichia; submarginal vein with long macrochaetae and 2-3 hypochaetae opposite to basal macrochaeta; postmarginal vein $0.9 \times$ as long as stigmal vein, marginal vein + parastigma about $5 \times$ as long as stigmal vein, the latter distinctly sessile. Hind wing (Fig. 13) about $7 \times$ as long as wide; blade uniformly setose, hyaline; longest marginal cilia about as long as wing's maximal width. Coxae lightly sculptured.

Metasoma (Fig. 15). Petiole about $2 \times$ as wide as long. Ovipositor occupying 1/2-3/5 length of gaster, slightly exserted; ovipositor length/metatibia length ratio $1.1: 1.0$

Measurements (holotype). Body length: $1.05 \mathrm{~mm}$. Relative measurements (as length or length/width): Antenna: scape: 11/3; pedicel: 6/3; F1: 2.5/2.3; F2: 2/2.5; clava: 7+2/4.5, C1: 3, C2: 4, spicula: 2. Forewing: 65/23; lon- 


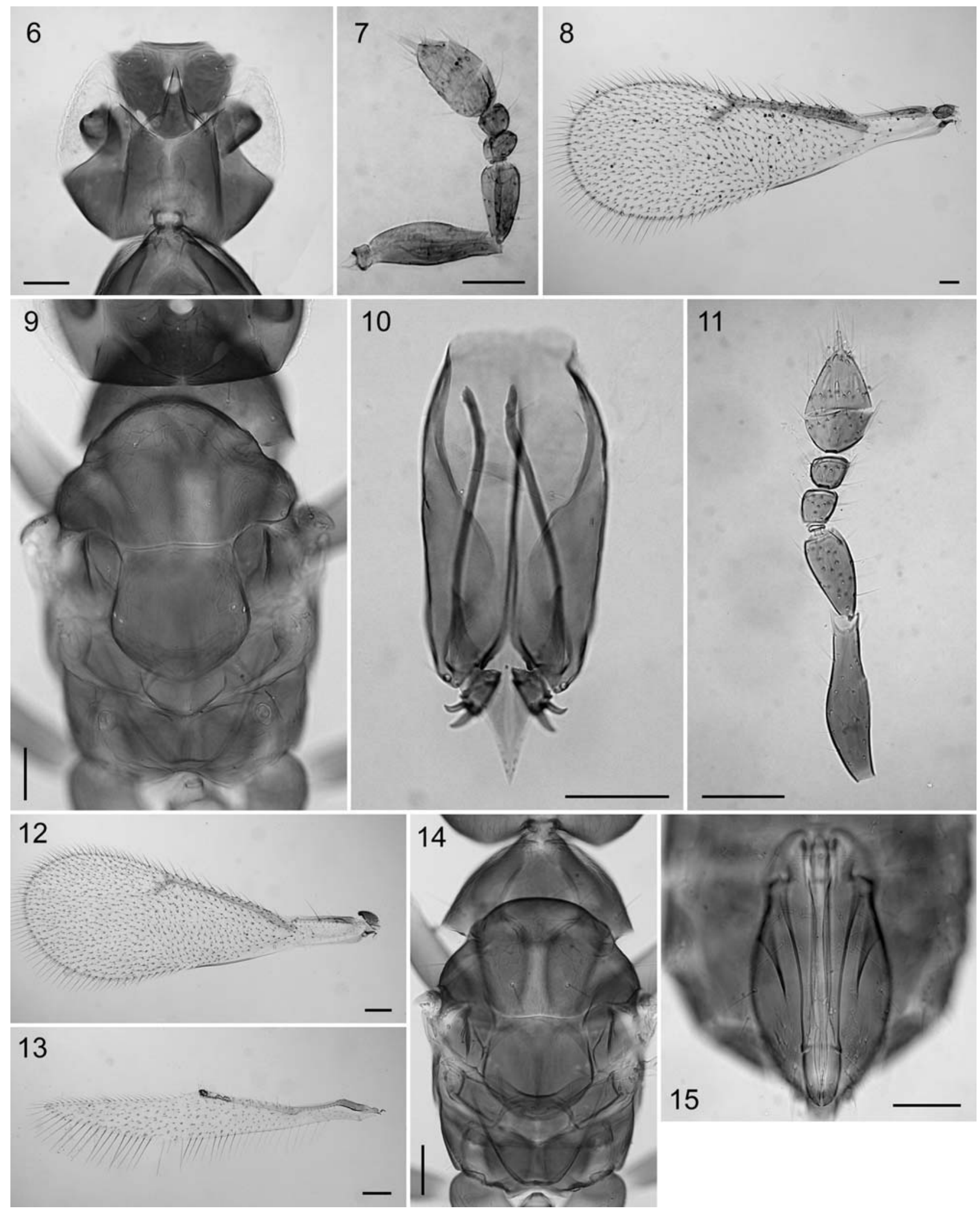

Figs 6-15: Ceranisus bozovaensis (Doğanlar). 6-10 - male, 6 - head in dorsal view; 7 - antenna; 8 - forewing; 9 - mesosoma; 10 - genitalia; 11-15 - female; 11 - antenna; 12 - forewing; 13 - hind wing; 14 - mesosoma; 15 - genitalia. Scale bars $=0.05 \mathrm{~mm}$.

gest marginal cilia: 5. Hind wing: 57/8; longest marginal cilia: 7. Ovipositor: 17.

Male. Description was given by Doğanlar (2003) (as female). Antenna (Fig. 7) with scape $3.2 \times$ as long as wide; pedicel and flagellum as in female but F1 quadrate. Mesosoma as in Fig. 9. Marginal vein of the forewing notably and significantly expanded, particularly basally (Fig. 8). Body length about $1.00 \mathrm{~mm}$. Relative measure- 

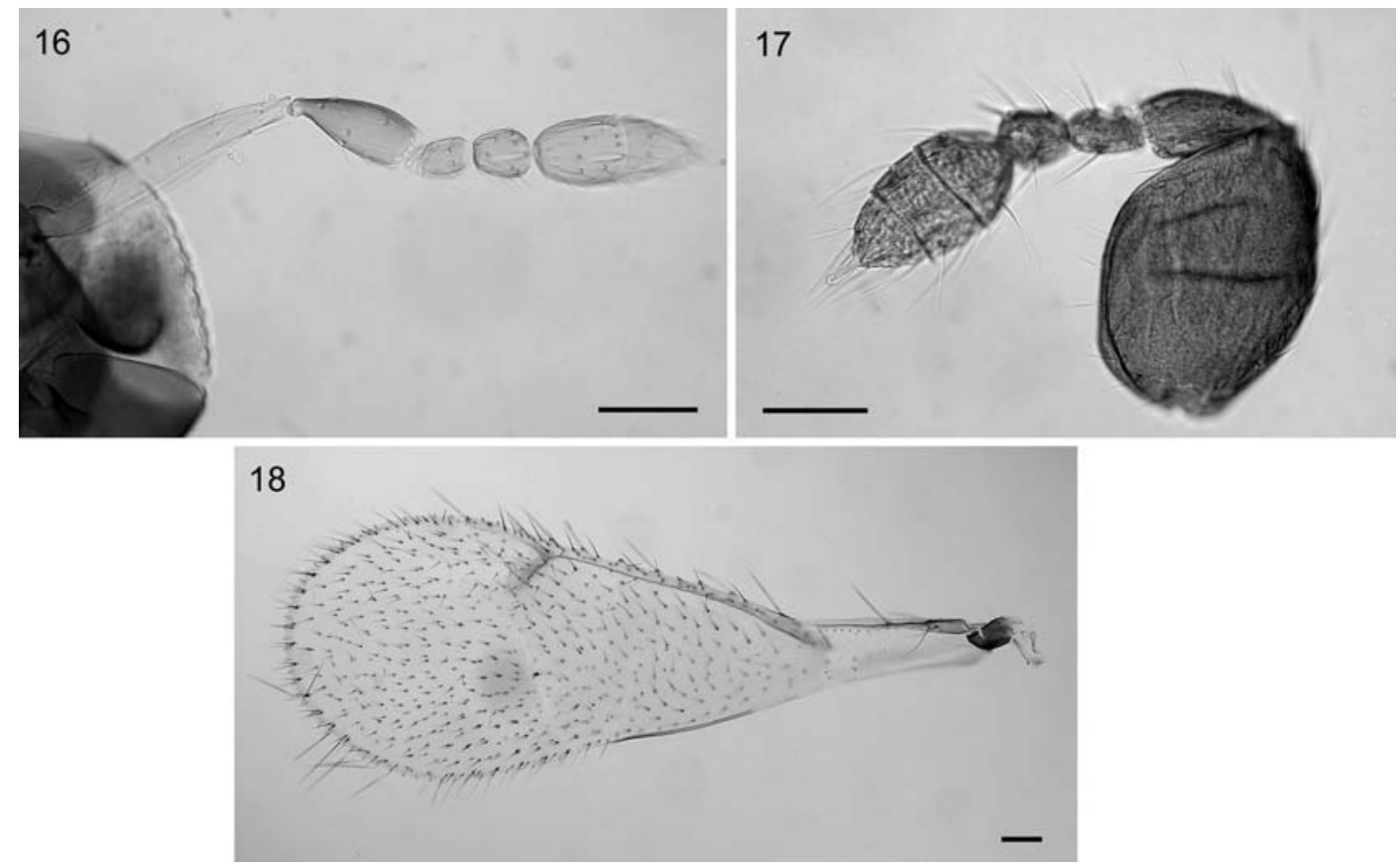

Figs 16-18: Ceranisus pacuvius (Walker). 16 - female antenna; 17 - male antenna; 18 - female forewing. Scale bars $=0.05 \mathrm{~mm}$.

ments, as length or length/width: Antenna: scape: $9.5 / 3$; pedicel: $5.5 / 3$; F1: 2/2.2; F2: 2/2.2; clava: $6.5+1.5 / 4, \mathrm{C} 1$ : 2.5, C2: 2, C3: 2, spicula: 1.5. Genitalia as in Fig. 10.

Diagnosis. This species is similar to C. lepidotus in having the head and mesosoma reticulate; their antennae in both sexes are also very similar. It differs from C. lepidotus in having the mesoscutum with broad meshed reticulate sculpturing and the dorsum of head and mesosoma with bluish tinge, and also in notably expanded marginal vein (especially basally) of the male forewing in the majority of specimens. In C. lepidotus, dorsum of the head and mesosoma have a metallic greenish luster and the marginal vein of the male forewing is only slightly thickened in its whole length.

Hosts. Unknown.

\section{Ceranisus menes (Walker, 1839)}

See Triapitsyn \& Headrick (2005) for the diagnosis and illustrations of $C$. menes and also Triapitsyn (2005) for the list of its synonyms, distribution, etc. Loomans \& van Lenteren (1995) listed the known hosts of this species.

Type locality. Near London, England, UK.

Material examined. (ICMKU). Turkey: Hatay, Antakya, Adiyaman, Gölbaşi, 5.ix.2005, E. Çikman, 5 ㅇ (swept from lentil field). Serinyol, 65 m, 17.iii.2005, M. Doganlar, 34 ㅇ․

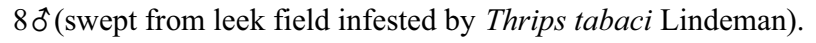

Comments. This common cosmopolitan species was also recently recorded from Turkey (Kemer) by Triapitsyn (2005).

\section{Ceranisus pacuvius (Walker, 1841)}

Figs 16-18

See Triapitsyn (2005) for the diagnosis, illustrations, list of synonyms, and distribution of C. pacuvius.
Loomans \& van Lenteren (1995) listed the known hosts of this species.

Type locality. Near London, England, UK.

Material examined. (ICMKU). Turkey: Kahramanmaraş, v.2003, A. Yiğit, 2 ? (swept from Medicago sativa field). Şanliurfa, Birecik, Arat Mt., $37^{\circ} 03^{\prime} \mathrm{N}, 38^{\circ} 08^{\prime} \mathrm{E}, 800$ m, 6.v.2005, M. Doğanlar, 9 ㅇ, $2 \hat{\sigma}$ (swept from lentil field).

Comments. This species is recorded for the first time from Turkey.

ACKNOWLEDGEMENTS. We thank V.V. Berezovskiy (UCRC) for point- and slide-mounts. The first author also thanks the researchers mentioned as collectors and Alexander von Humboldt-Stiftung for donation of the laboratory equipment.

\section{REFERENCES}

Cameron E.A., Teulon D.A.J., Triapitsyn S.V. \& Tunç I. 2004: The discovery of a new species of Ceranisus from southwestern Turkey. BioControl 49: 373-383.

DoĞANLAR M. 2003: A new genus and a new species of Entedontinae (Hymenoptera: Eulophidae) from southeastern Anatolia, Turkey. Turk. J. Zool. 27: 181-185.

ERDÖs J. 1966: Nonnullae Eulophidae novae Hungaricae (Hymenoptera, Chalcidoidea). Ann. Hist. Nat. Mus. Natn. Hung. (Zool.) 58: 395-420.

GiBson G.A.P. 1997: Chapter 2. Morphology and terminology. In Gibson G.A.P., Huber J.T. \& Woolley J.B. (eds): Annotated Keys to the Genera of Nearctic Chalcidoidea (Hymenoptera). Ottawa, NRC Research Press, pp. 16-44.

Graham M.W.R. DE V. 1963: Additions and corrections to the British list of Eulophidae (Hym., Chalcidoidea), with descriptions of some new species. Trans. Soc. Br. Entomol. 15(9): $167-275$.

Loomans A.J.M. 2003: Parasitoids as Biological Control Agents of Thrips Pests. PhD Thesis, Wagenningen University, Wageningen, $200 \mathrm{pp}$. 
Loomans A.J.M. \& van Lenteren J.C. 1995. Biological control of thrips pests: a review on thrips parasitoids. In Loomans A. J.M., van Lenteren J.C., Tommasini M.G., Maini S. \& Riudavets J: Biological Control of Thrips Pests. Wageningen Agricultural University Papers, 95-1. Wageningen, Veenman Drukkers, pp. 89-193 + 195-201 (Appendix).

Schauff M.E. 1991: The Holarctic genera of Entedoninae (Hymenoptera: Eulophidae). Contr. Am. Entomol. Inst. 26(4): $1-109$.

TRIAPITSYN S.V. 2005: Revision of Ceranisus and the related thrips-attacking entedonine genera (Hymenoptera: Eulophidae: Entedoninae) of the world. Afr. Invert. 46: 261-315.
Triapitsyn S.V. \& Headrick D.H. 1995: A review of the Nearctic species of the thrips-attacking genus Ceranisus Walker (Hymenoptera: Eulophidae). Trans. Am. Entomol. Soc. 121: 227-248.

Triapitsyn S.V. \& Morse J.G. 2005: A review of the species of Ceranisus Walker (Hymenoptera: Eulophidae) in the New World. Trans. Am. Entomol. Soc. 131: 69-86.

WALKER F. 1841: [No title, legends to plates (drawings by A.H. Haliday)]. The Entomologist 1[1840-1842]: v-vi + pl. A-P.

Received March 28, 2006; revised and accepted September 8, 2006 